\title{
An out-patient nutritional supplementation programme in COPD patients
}

\author{
M.K. Sridhar*, A. Galloway**, M.E.J. Lean\#, S.W. Banham*
}

An out-patient nutritional supplementation programme in COPD patients. M.K. Sridhar, A. Galloway, M.E.J. Lean, S.W. Banham. CERS Journals Ltd 1994.

ABSTRACT: Studies that have assessed the role of nutritional supplementation in patients with emphysematous chronic obstructive pulmonary disease (COPD) have shown conflicting results. Improved respiratory muscle strength and exercise capacity have been demonstrated following intensive and costly nutritional support programmes under controlled conditions. We have evaluated a simple programme of out-patient nutritional support in a clinical setting.

Twelve malnourished COPD patients ( 9 male and 3 female; mean age $66 \mathrm{yrs}$; $<90 \%$ ideal body weight) were studied. Forced vital capacity (FVC), forced expiratory volume in one second $\left(\mathrm{FEV}_{1}\right)$, estimation of maximal oxygen uptake $\left(\dot{\mathrm{V}}_{2} \mathrm{max}\right)$ during exercise, respiratory muscle strength (PImax and PEmax), and measurement of body weight, height, triceps skinfold thickness, and mid-arm muscle circumference were performed before and after a 4 month period of out-patient nutritional support. Patients were advised by a dietician on increasing their daily caloric intake by a minimum of $50 \%$ above estimated daily energy expenditure.

Three patients withdrew from the study. The mean increase in body weight in the nine remaining patients after 4 months of supplementation was $0.3 \mathrm{~kg}$. There was no significant improvement in the anthropometric measures, lung function, respiratory muscle strength or $\dot{\mathrm{V}}_{2}$ max for the group as a whole. Three patients who gained more than $1 \mathrm{~kg}$ weight were from a higher socioeconomic background compared with those who failed to do so.

We conclude that achieving weight gain and improving lung function by means of simple out-patient nutritional programmes in a clinical setting is difficult. Eur Respir J., 1994, 7, 720-724.
*Dept of Respiratory Medicine, "University Dept of Human Nutrition, **Dept of Dietetics, Glasgow Royal Infirmary, Scotland.

Correspondence: M.K. Sridhar

Centre for Respiratory Investigation Glasgow Royal Infirmary

Glasgow, G4 OSF

Scotland

Keywords: Chronic obstructive pulmonary disease

malnutrition

nutritional supplementation

Received: June 41993

Accepted after revision November 211993

MKS was funded by a Clinical and Biomedical Research grant from the Scottish Office Home and Health Department.
Malnutrition is a well-recognized feature of patients suffering from chronic obstructive pulmonary disease (COPD) [1]. A retrospective analysis of the data from the National Institute of Health Positive Pressure Breathing trial involving 779 patients with COPD showed that malnutrition (defined as $<90 \%$ ideal body weight) was not only widely prevalent $(24 \%)$ but, also, that it was an important adverse prognostic factor [2]. The question of nutritional support in these patients and, in particular, its effect on their lung function, respiratory muscle strength and exercise capacity has been addressed by various studies [3-6]. The role of nutritional support in COPD patients has also been the focus of a recent review of pulmonary rehabilitation techniques [7], which concluded that achieving weight gain in these patients is difficult, but when achieved, it is associated with a statistically significant improvement in respiratory muscle strength (RMS) and exercise capacity. The studies which showed an improvement in RMS and exercise capacity following nutritional supplementation involved intensive short-term refeeding techniques [3], or closely supervised out-patient programmes $[4,6]$, with significant cost implications. However, if nutritional therapy is to have a practical role in rehabilitation programmes for COPD, simple out-patient programmes are required. In this context, we present the result of a study of a simple, sustainable out-patient programme of nutritional support in COPD patients.

\section{Patients and methods}

Twelve patients (9 male, 3 female; mean age 66 yrs were studied as out-patients. All patients had emphysema as manifested by a forced expiratory volume in one second/forced vital capacity $\left(\mathrm{FEV}_{1} / \mathrm{FVC}\right)$ ratio of $<60 \%$ predicted, and a carbon monoxide single-breath diffusing capacity of $<60 \%$ predicted [8]. All patients were $<90 \%$ ideal body weight (IBW) as determined from the mid-point of the weight range for sex, height and frame in the Metropolitan Life Insurance Company tables [9], or had lost $>5 \%$ of their body weight in the previous six months. All patients were current or ex-smokers. None of them suffered from cancer, diabetes, malabsorption or any other illness that could cause weight loss. Patients who suffered from overt cor pulmonale (ankle oedema, 
raised jugular venous pressure) or other cardiac disease were excluded from the study. Patients entered into the study were considered clinically stable and free of intercurrent respiratory tract infection. All patients used inhaled and/or oral bronchodilator therapy. None was receiving oral steroid therapy, but four patients were on long-term inhaled steroids (more than 2 yrs) at a dose of $\leq 800 \mu \mathrm{g}$ beclomethasone dipropionate daily.

\section{Anthropometry}

Body height was measured to the nearest $0.5 \mathrm{~cm}$ with the patient standing barefoot. Body weight was measured to the nearest $0.1 \mathrm{~kg}$ by a beam scale with the patient in light clothing and without shoes (Weylux Model 424, UK). Body frame was estimated from wrist circumference measurements. Triceps skinfold thickness (TSF) was measured to the nearest $0.2 \mathrm{~mm}$ using Holtain skinfold calipers and standard techniques [10]. Mid-arm circumference (MAC) was measured and mid-arm muscle circumference (MAMC) derived from the formula: MAMC=MAC- 3.14 (TSF).

\section{Blood biochemistry}

Serum albumin was measured. C-reactive protein levels were estimated as an indicator of the presence of an acute phase response and confirmed to be normal before the patient was entered into the study.

\section{Calorimetry}

Indirect calorimetry was performed on an out-patient basis in all patients using a ventilated hood system (Deltatrac metabolic monitor, Datex Instrumentarium Corp, Helsinki, Finland). Patients were tested in a separate laboratory after an overnight fast of at least $10 \mathrm{~h}$. After a resting period of $20 \mathrm{~min}$, oxygen consumption and carbon dioxide production were estimated for a period of $20 \mathrm{~min}$ with the patient in the semi-recumbent position. The data obtained in the last $15 \mathrm{~min}$ were used to estimate resting energy expenditure (REE) if there was less than $5 \%$ minute to minute variation in the oxygen consumption measurement. REE was calculated using the formula of WEIR [11].

\section{Lung function tests}

$\mathrm{FEV}_{1}$ and FVC were measured using a whole body plethysmograph (P.K. Morgan Ltd, UK) [12]. Diffusing capacity was measured by the single-breath technique [13].

\section{Respiratory muscle strength}

Maximal inspiratory and expiratory mouth pressures (PImax and Pemax) were measured using apparatus based on that of Black and Hyatt [14]. Pimax was measured from functional residual capacity (FRC) and PEmax from total lung capacity (TLC). The highest of three technically satisfactory measurements was taken as the value used for analysis in each case.

\section{Exercise capacity}

Symptom-limited exercise tests were carried out using an electrically braked bicycle ergometer (Siemens Ltd), with the patient breathing through a low dead space, low resistance valve box. The valve box incorporated a turbine ventilometer on the inspired limb for the measurement of ventilation. Expired gas was analysed for oxygen and carbon dioxide by an infra-red spectrometer and paramagnetic analyser, respectively, (P.K. Morgan Ltd, UK). After a 2 min rest period, while seated on the bicycle, the patients were instructed to cycle with no additional load for $2 \mathrm{~min}$. Thereafter, the load was increased by $25 \mathrm{~W}$ every $2 \mathrm{~min}$, until symptoms limited exercise. Two trial tests were performed on separate occasions before the first exercise test to familiarize the patients with the equipment and to avoid confounding of the results by a training effect.

The measures of respiratory function, exercise capacity and nutritional status were made before and after a four month period of nutritional support.

\section{Dietary assessment and nutrition}

The patients were assessed by a senior dietician on enrolment into the study. Mean daily carbohydrate, protein, fat and energy intake was estimated from a 7 day recall, on two separate occasions. The patients were then advised on increasing their total caloric intake to at least $50 \%$ above predicted daily energy expenditure, which was calculated as 1.3 times measured REE (sedentary lifestyle); recommended protein intake to at least 1.5 $\mathrm{g} \cdot \mathrm{kg}^{-1}$. Nutritional supplementation was by the use of proprietary supplements. The patients were allowed to choose the nature (liquid, pudding) and flavour of the supplements from a wide range of proprietary preparations offered to them (Buildup, Fortisip, Maxijul®). A fortnight's supply of the supplement was provided initially, and the patients were asked to seek replenishments as required. Where applicable, the patient's spouse was also instructed on the aims and nature of the dietary intervention. The patients' understanding of the dietary instructions were confirmed by one of the investigators (MKS). After the first interview, the patients attended a monthly dietetic review, at which adherence to the recommended diet was confirmed verbally. Nutritional supplementation was continued for a period of four months. The dietary advise was provided during routine clinic hours.

\section{Statistical analysis}

The anthropometric measures, serum albumin, tests of lung function, exercise capacity and RMS before and after nutritional supplementation were compared using 
Table 1. - Energy balance details of study population

\begin{tabular}{|c|c|c|c|c|c|c|}
\hline $\begin{array}{l}\text { Patient } \\
\text { No. }\end{array}$ & Sex & $\begin{array}{l}\text { Age } \\
\text { yrs }\end{array}$ & $\%$ IBW & $\begin{array}{r}\mathrm{R} \\
\mathrm{kcal} \cdot \mathrm{day}^{-1} \\
\end{array}$ & $\begin{array}{l}\text { EE } \\
(\% \text { pred })\end{array}$ & $\begin{array}{l}\text { Daily caloric intake } \\
(\% \text { pred daily EE)* }\end{array}$ \\
\hline 1 & M & 79 & 89 & 1225 & (108) & 1899 (119) \\
\hline 2 & $\mathrm{~F}$ & 64 & 70 & 1024 & (111) & $1387 \quad(104)$ \\
\hline 3 & M & 72 & 82 & 1087 & (96) & 1554 (110) \\
\hline 4 & $\mathrm{~F}$ & 65 & 71 & 1187 & (112) & 1635 (106) \\
\hline 5 & M & 67 & 92 & 1484 & (126) & 1982 (103) \\
\hline 6 & M & 67 & 76 & 1358 & (110) & 1617 (91) \\
\hline 7 & M & 64 & 84 & 1630 & (108) & 2159 (101) \\
\hline 8 & M & 60 & 66 & 1039 & (114) & $1337 \quad(98)$ \\
\hline 9 & M & 67 & 92 & 1285 & (109) & $1798 \quad(107)$ \\
\hline $10 * *$ & M & 60 & 85 & 1515 & (117) & 1890 \\
\hline $11 * *$ & $\mathrm{~F}$ & 64 & 82 & 1057 & (99) & 1516 (110) \\
\hline $12 * *$ & M & 62 & 77 & 1051 & (102) & 1270 \\
\hline
\end{tabular}

IBW: ideal body weight; REE: resting energy expenditure; EE: energy expenditure. *: predicted daily energy expenditure: $1.3 \times$ measured REE; **: did not complete study.

Table 2. - Indicators of nutritional status before and after nutritional supplementation

\begin{tabular}{|c|c|c|c|c|c|c|c|c|}
\hline \multirow{2}{*}{$\begin{array}{l}\text { Patient } \\
\text { No. }\end{array}$} & \multicolumn{2}{|c|}{ Body weight $\mathrm{kg}$} & \multicolumn{2}{|c|}{ TSF mm } & \multicolumn{2}{|c|}{ MAMC $\mathrm{cm}$} & \multicolumn{2}{|c|}{ Albumin $\mathrm{g} \cdot \mathrm{dl}^{-1}$} \\
\hline & $\mathrm{BS}$ & AS & BS & AS & $\mathrm{BS}$ & AS & BS & AS \\
\hline 1 & 55 & 58.3 & 5.2 & 5.6 & 22.4 & 22.2 & 46 & 43 \\
\hline 2 & 31 & 32 & 2.8 & 2.8 & 17.1 & 17.2 & 42 & 40 \\
\hline 3 & 51 & 49.8 & 3.8 & 3.8 & 20.3 & 20.3 & 42 & 40 \\
\hline 4 & 41.5 & 42.8 & 3.6 & 3.8 & 16.9 & 16.8 & 44 & 49 \\
\hline 5 & 54.5 & 53.4 & 6.8 & 6.4 & 21.8 & 22.0 & 47 & 44 \\
\hline 6 & 53.2 & 53.0 & 7.0 & 7.0 & 19.8 & 19.8 & 43 & 45 \\
\hline 7 & 68.4 & 73.0 & 8.0 & 8.8 & 21.4 & 22.0 & 49 & 50 \\
\hline 8 & 35.4 & 35.0 & 3.0 & 3.2 & 17.0 & 17.0 & 39 & 42 \\
\hline 9 & 54.6 & 52.3 & 3.8 & 3.4 & 24.8 & 24.9 & 43 & 48 \\
\hline
\end{tabular}

TSF: triceps skinfold thickness; MAMC: mid-arm muscle circumference; BS: before supplementation; BS: before supplementation; AS: after supplementation.

paired Student's t-test. The mean values of the various measurements were considered significantly different when the probability of the differences of that magnitude, assuming the null hypothesis to be correct, fell below $5 \%$ (i.e. $\mathrm{p}<0.05$ ).

The study was approved by the Hospital Ethics Committee and the patients gave their informed consent.

\section{Results}

Three patients withdrew from the study. Two withdrew due to intolerance of the supplements, one after the first fortnight and another after a month. Unacceptable taste and abdominal bloating after taking the supplements were given as reasons for intolerance to the supplements by the two patients. One patient withdrew due to a protracted episode of intercurrent lower respiratory tract infection.

Mean resting energy expenditure for the group was $109 \%$ predicted (range 96-126\%) [15]. Four of the 12 patients (Nos 6, 8, 10 and 12) were in a state of net negative energy balance (table 1). Of the nine patients, a weight gain of more than $1 \mathrm{~kg}$ was achieved in only three; these three patients were from a higher socioeconomic class (Class 2) than the patients in whom nutritional supplementation was unsuccessful (Class 4-5).
There was no significant change in the nutritional status, $\mathrm{FEV}_{1}, \mathrm{RMS}$ or $\dot{\mathrm{V}}_{2}$ max after the four month period of supplementation in the nine patients who completed the study (table 2 and 3 ).

\section{Discussion}

Well-designed, randomized, controlled studies have shown that successful nutritional therapy is accompanied by an improvement in various measures of respiratory function and symptoms [3, 4]. The aim of this study was to see whether the beneficial effect of supplementary nutritional therapy, as demonstrated under wellcontrolled experimental conditions, could be extended to the wider area of clinical practice. Our study suggests that although weight gain and improvement in functional status may be achieved by some individuals under these circumstances, this approach is ineffective for the majority, and a number of practical issues need to be addressed before nutritional therapy is accepted as routine clinical practice.

All studies of out-patient nutritional support in malnourished COPD patients point to the fact that these patients are unable to maintain an increased caloric intake over a long period. In a recent study [6], the rate of weight gain achieved during a stay in a clinical research 
Table 3. - Indicators of lung, respiratory muscle function and exercise capacity before and after nutritional supplementation

\begin{tabular}{|c|c|c|c|c|c|c|c|c|}
\hline \multirow{2}{*}{$\begin{array}{l}\text { Patient } \\
\text { No. }\end{array}$} & \multicolumn{2}{|c|}{$\mathrm{FEV}_{1} l$} & \multicolumn{2}{|c|}{$\dot{\mathrm{V}}_{\mathrm{O}_{2}} \max l \cdot \mathrm{min}^{-1}$} & \multicolumn{2}{|c|}{ Pemax $\mathrm{cmH}_{2} \mathrm{O}$} & \multicolumn{2}{|c|}{ PImax $\mathrm{cmH}_{2} \mathrm{O}$} \\
\hline & $\mathrm{BS}$ & AS & BS & AS & BS & AS & BS & AS \\
\hline 1 & 0.80 & 0.82 & 0.62 & 0.66 & 100.3 & 100.8 & 58.7 & 58.9 \\
\hline 2 & 0.72 & 0.69 & 0.51 & 0.48 & 70.1 & 68.3 & 40.4 & 41.5 \\
\hline 3 & 0.65 & 0.63 & 0.49 & 0.52 & 96.6 & 97.2 & 50.0 & 48.0 \\
\hline 4 & 0.60 & 0.62 & 0.28 & 0.36 & 63.0 & 66.1 & 31.0 & 33.9 \\
\hline 5 & 1.03 & 0.99 & 0.99 & 0.72 & 100.4 & 98.2 & 49.4 & 49.0 \\
\hline 6 & 1.15 & 1.20 & 1.09 & 0.93 & 83.6 & 80.7 & 41.8 & 41.0 \\
\hline 7 & 1.67 & 1.72 & 0.90 & 0.94 & 122.5 & 126.4 & 75.5 & 78.4 \\
\hline 8 & 0.60 & 0.60 & 0.49 & 0.35 & 73.0 & 71.2 & 45.8 & 47.3 \\
\hline 9 & 1.73 & 1.61 & 1.33 & 1.20 & 148.4 & 151.0 & 70.6 & 68.5 \\
\hline
\end{tabular}

$\dot{\mathrm{V}}_{2}$ max: maximal oxygen uptake on exercise; Pemax: maximal expiratory pressure; PImax: maximal inspiratory pressure; BS: before supplementation; AS: after supplementation.

unit could not be sustained in the out-patient setting, despite the provision of full and intensive nutritional support. Thus, providing adequate and appropriate nutritional support alone does not in itself guarantee an improvement in the nutritional status of these patients. A number of factors could account for this finding. It has been pointed out that patients tend to decrease their own food intake whilst receiving enteral formulae, and do not in fact improve their caloric intake whilst on nutritional supplements [16]. Breathlessness, produced by the effort of eating, may also limit food intake. Perception of nutritional therapy as making only a minor contribution to their well-being might be another factor that may influence compliance with dietary advise and response to therapy. No attempt was made in our study to objectively confirm adherence to the dietary instructions provided, as it was felt that under clinical conditions, which our study aimed to mimic, such measures were clearly impractical.

Also worthy of note, is our finding that the three patients who gained weight in our study were from a higher socio-economic class. Unemployment, smoking habits, poor working and housing conditions are amongst the various factors that may influence the outcome of all medical treatment including nutritional therapy [17].

Our findings have to be interpreted, bearing in mind that the study did not have a control group and that the number of patients studied was small. Also, it is possible that the workload increments used in the study (25 W) may have resulted in the underestimation of the patients' exercise capacity and rendered the exercise test a less sensitive end-point in the assessment of the beneficial effects of nutritional therapy. Despite these limitations, we believe the results of our study are of value in highlighting the practical difficulties in establishing a successful nutritional support programme in a clinical context.

Taken together with a recent study in the same field, which concluded that although nutritional therapy is capable of producing significant clinical improvement in patients with COPD, it is costly, time-consuming and of limited therapeutic magnitude [6], it would be appropriate to conclude that conventional nutritional supplementation per se is of little value in the management of patients with COPD. We believe that further studies in the out-patient setting should now assess the effect of nutritional therapy, in conjunction with attempts at promoting anabolism either by pharmacological means (anabolic steroids) [18], or physical training (exercise prescription and respiratory muscle training).

\section{References}

1. Wilson DO, Rogers RM, Hoffman RM. Nutrition and chronic lung disease. Am Rev Respir Dis 1985; 132: 1347-1365.

2. Wilson DO, Rogers RM, Wright EC, Anthonisen NR. Body weight in chronic obstructive pulmonary disease: The National Institute of Health Intermittent Positive pressure Breathing Trial. Am Rev Respir Dis 1989; 139: 1435-1438.

3. Wilson DO, Rogers RM, Sanders MH, Pennock B, Reilly JJ. Nutritional intervention in malnourished patients with emphysema. Am Rev Respir Dis 1986; 134: 672-677.

4. Efthimiou J, Fleming J, Gomes C, Spiro SG. The effect of supplementary oral nutrition in poorly nourished patients with chronic obstructive pulmonary disease. Am Rev Respir Dis 1988; 137: 1075-1082.

5. Knowles JB, Faibarn MS, Wiggs BJ, Chan-Yan C, Pardy RL. Dietary supplementation and respiratory muscle performance in patients with COPD. Chest 1988; 93(5): 977-983.

6. Rogers RM, Donahoe M, Constanino J. Physiological effects of oral supplemental feeding in malnourished patients with chronic obstructive pulmonary disease. Am Rev Respir Dis 1992; 146: 1511-1517.

7. Fitting JW, Spiro SG. Nutrition in chronic obstructive pulmonary disease. Eur Respir Rev 1991; 1(6): 511-519.

8. Gelb AF, Gold WM, Wright RR, Bruch HR, Nadel JA. Physiologic diagnosis of subclinical emphysema. $\mathrm{Am}$ Rev Respir Dis 1983; 107: 50-63.

9. Metropolitan Life Insurance Company weight standards for men and women. New York: Metropolitan Life, 1983.

10. Durnin JVGA, Rahaman MM. The assessment of the amount of fat in the human body from measurement of skinfold thickness. Br J Nutr 1967; 21: 681.

11. Weir JB. New methods for calculating metabolic rate with special reference to protein metabolism. $J$ Physiol 1949; 109: 1-9.

12. Grimby G, Soderholm B. Spirometric studies in normal subjects. III. Static lung volumes and maximal voluntary 
ventilation in adults with a note on physical fitness. Acta Med Scand 1963; 173: 199-206.

13. Burrows B, Kasik K, Niden AH, Barclay WR. Clinical usefulness of the single breath pulmonary diffusing capacity test. Am Rev Respir Dis 1961; 84: 789-806.

14. Black LF, Hyatt RE. Maximal respiratory pressures: normal values and relationships to age and sex. Am Rev Respir Dis 1969; 99: 669-672.

15. Harris JA, Benedict FG. Biometric studies of basal metabolism in man. Washington, DC. Carnegie Institute, 1919 (publication No. 27A).
16. Lewis MI, Belman MJ, Dorr-Uyemura L. Nutritional supplementation in ambulatory patients with chronic obstructive pulmonary disease. Am Rev Respir Dis 1987; 135: 1062-1068.

17. Whitehead M, Dahlgren G. What can be done about inequalities in health? Lancet 1991; 338: 1059-1063.

18. Schols AMWJ, Soeters PB, Pluymers RJ, Mostert R, Wouters EFM. A placebo controlled trial on the effects of supplemental nutrition alone or combined with nandralone decanoate on body composition in depleted COPD patients. Am Rev Respir Dis 1992; 145: 645A. 